\title{
Towards a New Epistemology of Mathematics
}

\author{
Bernd Buldt • Benedikt Löwe · Thomas Müller
}

Received: 7 November 2007/ Accepted: 7 November 2007/Published online: 21 March 2008

(C) The Author(s) 2008

\begin{abstract}
In this introduction we discuss the motivation behind the workshop "Towards a New Epistemology of Mathematics" of which this special issue constitutes the proceedings. We elaborate on historical and empirical aspects of the desired new epistemology, connect it to the public image of mathematics, and give a summary and an introduction to the contributions to this issue.
\end{abstract}

B. Buldt

Department of Philosophy, Indiana University-Purdue University Fort Wayne (IPFW), 2101 East Coliseum Boulevard, Fort Wayne, IN 46805, USA

e-mail: buldtb@ipfw.edu

B. Löwe $(\bowtie)$

Institute for Logic, Language and Computation, Universiteit van Amsterdam,

Plantage Muidergracht 24, 1018 TV Amsterdam, The Netherlands

e-mail: bloewe@science.uva.nl

B. Löwe

Department Mathematik, Universität Hamburg, Bundesstraße 55, 20146 Hamburg,

Germany

B. Löwe

Mathematisches Institut, Rheinische Friedrich-Wilhelms-Universität Bonn, Beringstraße 1, 53115 Bonn, Germany

T. Müller

Departement Wijsbegeerte, Universiteit Utrecht, Heidelberglaan 6-8, 3584 CS Utrecht, The Netherlands

e-mail: thomas.mueller@phil.uu.nl

T. Müller

Institut für Philosophie, Rheinische Friedrich-Wilhelms-Universitt Bonn, Lennéstraße 39, 53113 Bonn, Germany 


\section{Introduction}

Mathematics has been regarded as a very special science. This assessment is upheld across widely different contexts: Philosophers have marvelled at and sometimes tried to imitate the security of mathematical results, sociologists have shunned from applying their observational techniques to mathematics, and the general publicwhile not necessarily embracing mathematics as their favourite science-acknowledges the special status of mathematics through widely accepted figures of speech such as "mathematical precision".

Philosophically speaking, the special status of mathematics seems to derive from its peculiar epistemology, which appears to be linked to a special technique, mathematical proof. While all sciences justify their results, only a few sciences claim to prove their results; among those, mathematics alone uses mathematical proof, which conveys to its results the characteristic mathematical objectivity that other sciences lack. This is, e.g., reflected in Descartes' skeptical argument in the Meditationes: Empirical knowledge is destroyed via the dream argument, whereas Descartes has to invoke a genius malignus to doubt mathematical knowledge in his thought experiment. According to the traditional philosophical analysis, mathematical theorems are a priori truths about acausal, non-spatio-temporal objects. Working mathematicians themselves have a strong feeling that they are manipulating or dealing with objects that provide resistance (Dilthey's Widerstandsempfinden).

An adherent of the traditional, foundationalist view would subscribe to the following claims about mathematics: "Mathematical statements are objectively true or false", "There are no disputes about the validity of a mathematical statement once it is established", "The history of mathematics doesn't know any revolutions", 1 "Mathematics is a unique science; an 'epistemic exception",.2

If foundationalism is correct and the special epistemic status of mathematics really derives from its fundamental technique, i.e., mathematical proof, we should then be able to describe what that is. Until the end of the 19th century, mathematics did not have a precise answer to this question, but then the foundations of mathematics became a central research interest. This resulted in a widely accepted notion of formal derivation as the explication of mathematical proof. According to this doctrine, the objectivity of mathematics rests on the pure form of mathematical argumentation, an example of which can be seen in Fig. 1 (in one particular formal system).

In mathematical practice, proofs are written down in a more condensed, semiformal style, an example of which is given in Fig. 2. The traditional view would consider these proofs enthymematic, leaving out technical detail for purely pragmatic reasons (Fallis 2003). Therefore, it effectively suppresses any epistemological questions about informal proofs by postulating that, for philosophical questions, the difference between actual proofs and formal derivations can be (properly) ignored; it is part of this traditional view that enthymematic proofs can be completed to formal derivations.

\footnotetext{
${ }^{1}$ Cf. Grattan-Guinness (2004, p. 163): "Mathematics shows much more durability in its attention to concepts and theories than do other sciences. For example Galen may not be of much use to modern medicine, but one can still read and use Euclid".

${ }^{2}$ Cf. Prediger (2006) for a discussion.
} 
Fig. 1 A formal derivation (in

Gentzen's sequence calculus)

$$
\frac{\frac{\Gamma^{\prime} \Delta, A}{\neg A, \Gamma^{\prime} \Delta}}{\frac{\neg A, \neg A, \Gamma^{\prime} \Delta}{\frac{\Gamma \Delta \Delta \Pi}{\Gamma, \Pi, A \Delta, \Delta, B}}}
$$

A closer look at mathematical practice leads to two important observations. First, the completion of enthymematic, semi-formal proofs to formal derivations almost never happens and hardly plays any rôle in the justification that mathematicians give for their theorems; second, also the production of semi-formal proofs in the style of Fig. 2 is only the final step of the mathematical research process. This final step, while important for the documentation of results and crucial for the careers of researchers, is not necessary for the acceptance of a proof by the mathematical community. For this, different forms of proof are much more relevant: informal sketches on the blackboard, or scribblings and drawing on napkins (see Fig. 3). Shouldn't these forms of proof replace the unrealistic notion of formal derivation in our epistemology of mathematics?

The ideal of uncontroversial checkability of mathematical arguments, however, seems to be related to formal derivations rather than scribblings on napkins. How can we uphold the view that mathematical controversies are impossible, if mathematical epistemology rests on a means of communication with no precise format? Possibly, we can't. Indeed, in the past years there have been prominent cases of mathematical proofs whose correctness was disputed for an extensive period: Andrew Wiles's proof of Fermat's last theorem, Grigori Perelman's proof of the Poincaré conjecture, or Thomas Hales's proof of the Kepler conjecture. ${ }^{3}$ These cases have triggered a genuine inner-mathematical debate ${ }^{4}$ which was duly noticed by the general public, as can be seen from the following quote from the German weekly magazine Die Zeit:

Erstaunlicherweise sind ... die meisten [mathematischen] Beweise keine Abfolge von Formeln, sondern sie sind in ganzen Sätzen gefasst, einige davon lauten “Wie man leicht sieht, gilt ...", "Ohne Beschränkung der Allgemeinheit kann man annehmen, dass .... . Es wimmelt nur so von Andeutungen, stillschweigenden Voraussetzungen und Appellen an den gesunden Menschenverstand. Was als Beweis akzeptiert wird und was nicht, ist eine soziale Konvention der mathematischen Community.

(Christoph Drösser, 27 April 2006) ${ }^{5}$

\footnotetext{
${ }^{3}$ For overviews of these results and a discussion of the proofs, cf. the survey papers (Faltings 1995; Mackenzie 2006; Morgan 2005), respectively.

4 A parallel case of an inner-mathematical debate is the so-called "Jaffe-Quinn debate", provoked by the paper (Jaffe and Quinn 1993) about the differing standards of proof in mathematical physics and in pure mathematics.

5 "Surprisingly, most mathematical proofs aren't sequences of formulae but formulated in complete sentences, some of which read 'It is easy to see that ...,' 'Without loss of generality we can assume that ...' All over the place, we find an abundance of allusions, tacit assumptions, and appeals to common sense. What counts as a proof and what does not is a social convention of the mathematical community".
} 


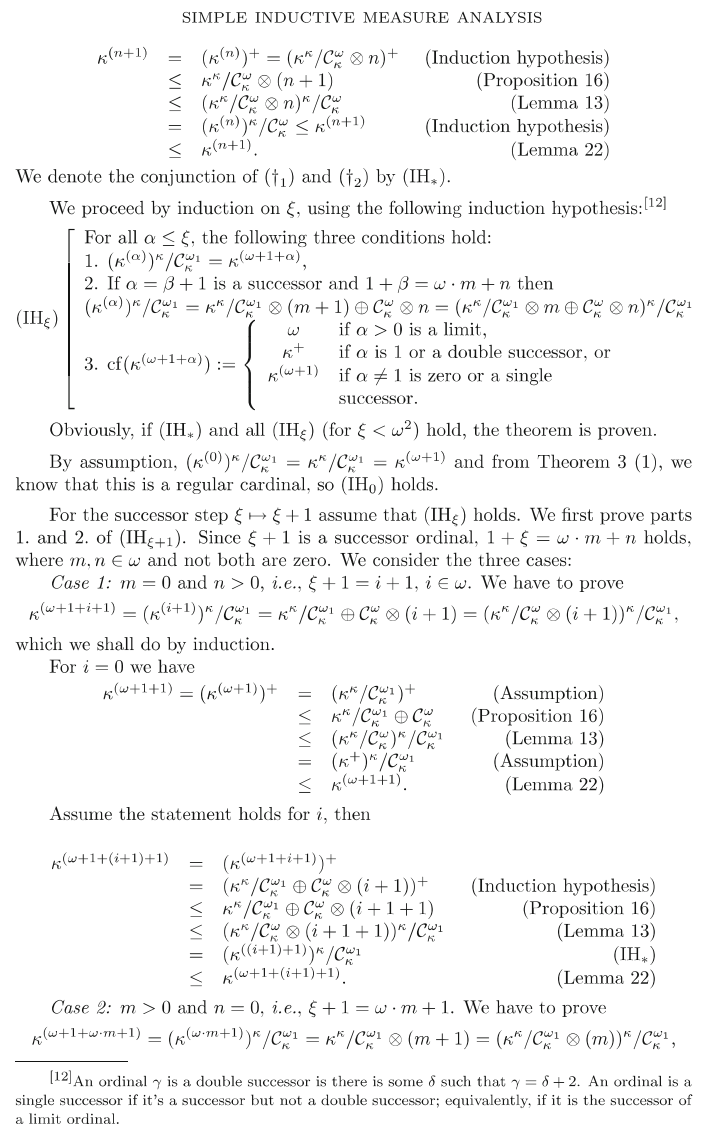

Fig. 2 A typical page from a mathematical research paper

These inner-scientific episodes, as witnessed by their public reflection, suggest that one should consider a revision of the foundationalist epistemology of mathematics. Indeed, philosophers like Wittgenstein, Lakatos, and Ernest have been advocating the view that mathematics should not be considered special; instead, they argue that its methodology is far more similar to that of the empirical sciences than what the usual image of a "proving discipline" with its emphasis on a specific formal methodology suggests. A radical denial of foundationalism is offered by social constructivism (Ernest 1998), an approach that many researchers in mathematics education embrace.

In our view, neither foundationalism nor social constructivism can offer sufficient explanations of mathematical practice. On one hand, mathematical knowledge does not solely emanate from formal derivations; on the other hand, the epistemic status of a mathematical theorem is decidedly different from research results in, e.g., paleoanthropology. This difference is not properly explained by social constructivism. It is therefore a desideratum that philosophers of mathematics develop a mediating position that strikes a balance between the special epistemic character of mathematics and the social embedding of mathematical practice. Some 

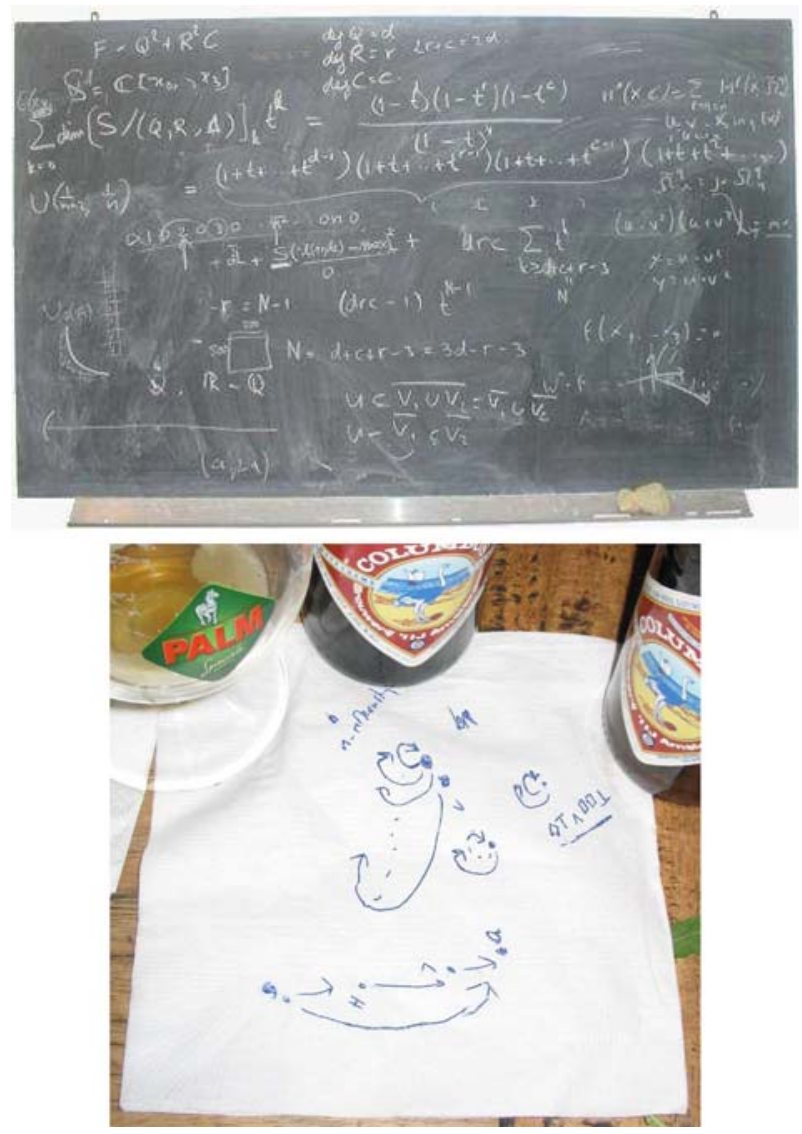

Fig. 3 Proofs from mathematical practice: a blackboard and a napkin. The picture of a napkin proof is included with permission of Ivan José Varzinczak

fruitful approaches exist, dispersed in the communities of mathematics education, sociology of science, and philosophy of mathematics, but a concerted interdisciplinary effort is necessary in order to develop a truly adequate new epistemology of mathematics.

This is the goal of the scientific network "Philosophy of Mathematics: Sociological Aspects and Mathematical Practice" (PhiMSAMP) in which researchers from the universities of Amsterdam, Bonn, Brussels, Darmstadt, Dortmund, Fort Wayne IN, Montréal QC, and Vienna collaborate. This collaboration brings together researchers from the fields of philosophy, mathematics, mathematics education, and history of mathematics in a series of workshops. The kick-off meeting, PhiMSAMP-0, took place in Bonn in May 2005. This special issue of Erkenntnis is a result of the first official activity of the network, the workshop PhiMSAMP -1 in Berlin in September 2006. Since then, the network has been involved in the organization of the international conference Perspectives on Mathematical Practice 2007 (PMP 2007) in Brussels and the organization of the Novembertagung 2007 in 
Bonn. The second official PhiMSAMP workshop, PhiMSAMP-2, was held in Utrecht in October 2007; it featured a day of tutorials on various empirical research techniques, in particular from sociology and cognitive science, that are intended to play an important rôle in the development of the new epistemology. The question of the special nature of mathematics will be raised again at PhiMSAMP-3 to be held in Vienna, May 2008, which has as its motto "Is Mathematics Special?"

Before giving an overview of the papers in this issue (Sect. 4), we shall now highlight two dimensions of our practice-oriented philosophy of mathematics, both of which we expect to become crucial for the development of our group's new, more adequate epistemology of mathematics. In Sect. 2, we shall pursue some historical lessons that indicate how some traditional epistemological conceptions came about and why they must fail. In Sect. 3 we sketch some general methodological issues of using empirical data in philosophy in general, and in epistemology of mathematics in particular.

\section{Lessons from History}

We argue, in this and the following subsection, that a historically informed view can no longer subscribe to a number of assumptions we find embraced without much ado by a majority of those who work in philosophy or mathematics. We claim in particular that philosophers and mathematicians usually assume a continuity of subject matters that doesn't survive closer scrutiny. Neither the objects of mathematics nor the philosophical reflection upon them display a continuity that would justify expressions like "the triangle from Aristotle to Atiyah" or "the philosophy of mathematics from Plato to Putnam".

In regards to mathematics we hold that the conceptual framework of mathematics has changed so dramatically that, say, identifying Greek numbers with modern axiomatic characterizations just seems outrageous. That it could seem to be otherwise is basically the product of a modern myth, Cartesian dualism.

In regards to philosophy we show that philosophy of mathematics started its career around 1,800 as a short-lived creature that sprang from Kant's epistemology and sunk into oblivion thereafter before it was reanimated by logical empiricism in the early 20th century. On both occasions, Kantians and logical empiricists had doctrinal reasons for assigning mathematics a distinguished epistemological status that would elevate it above the sciences. Without subscribing to Kantian or Viennese presuppositions, however, this alleged special status of mathematics becomes simply unfounded. We hence claim that the special epistemological status of mathematics (as traditionally understood and outlined above in Sect. 1) is another myth.

Kant once coined the expression "usurpatory concepts". He defined them as concepts for which, "though allowed to circulate by almost universal indulgence [...], no clear legal title, sufficient to justify their employment" 6 can be obtained. Kant was concerned about certain metaphysical notions, but we think that

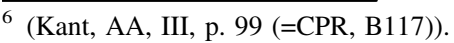


usurpatory concepts reflect a general phenomenon of language as it evolves over time. Concepts are introduced at a certain moment in time to satisfy then current needs; but over time they acquire a life of their own and either lose their original meaning and take on a metaphorical one, or they turn into red herrings. Examples are ubiquitous and easy to find; e.g., we still speak of "electrical currents" although the theory that electricity is a kind of fluid has been obsolete for a long time. The thesis, then, that we try to establish in this section is that (traditional) "philosophy of mathematics" is an usurpatory concept as well. Doing work in the philosophy of mathematics by starting from commonly accepted views about the Platonic character of mathematics and its special epistemological status is like researching electricity and assuming it is a fluid. ${ }^{7}$

A historical lesson from the philosophy of mathematics. In the year 1799, at a time when Fichte was still very close with Schelling and the two brothers August and Friedrich Schlegel, an idea emerged among them: the plan for a Jenaische Colonie, a house-sharing community in Berlin. This idea came with another one, namely, a plan for a new journal they would edit. One of the main motives for founding a journal was that Fichte thought it necessary to have a durchgreifende kritische Zeitschrift as an instrument not only to oppose the conservative camp but also "[um] gewaltiger in die Wissenschaft, und den Geist des Zeitalters einzugreifen". 8 Provisionally entitled Kritisches Institut, the journal was envisaged as a pragmatische Zeitgeschichte der Litteratur und Kunst. ${ }^{9}$ Fichte sketched the blueprint for the treatment of mathematics in the new journal as follows:

Mathematische Wissenschaften. Das Bekannte wird vorausgesetzt. Vielleicht verdienen neuerliche Entdeckungen in der Astronomie, und die combinatorische Analyse für das vergangene, ehrenvolle Meldung. Mangel einer Philosophie der Mathematik, und Nachtheile, die der Math.[ematik] daraus erwachsen; wird in der Zeitgeschichte fortgesezt, bis diesem Mangel einst abgeholfen wird".

(Fichte, III/4, p. 171) ${ }^{10}$

Fichte did hence not only notice the non-existence of a philosophy of mathematics but was also concerned that this might have detrimental effects for mathematics itself. Accordingly, the following year he urged Schelling to produce a Grundzüge einer Philosophie der Mathematik for the first volume of the journal. But Schelling, having too much on his plate already, tried to get (Adolph Karl August von) Eschenmayer involved instead who was a well-known medical doctor and natural philosopher.

\footnotetext{
7 In order to avoid excessive scholarly clutter, we will give explicit references only for those claims we expect to be unfamiliar to the average reader of this journal. The full version of the arguments, of which the current paragraph is a short excerpt from (Buldt 2004) and will be published separately (and partly also in Buldt $(\infty$ b) and Buldt and Van Kerkhove $(\infty))$ with rich historical evidence from various sources.

8 "have a more powerful influence on sciences and arts and the spirit of the age".

9 (Fichte, III/4, p. 169) (emphasis surpressed).

10 "Mathematical Sciences. We assume what is well-known. Recent discoveries in astronomy and the combinatorial analysis should possibly get their proper due. Lack of a philosophy of mathematics, and the disadvantages this causes for mathematics; to be continued in the section on current events until the situation is remedied".
} 
Nothing came out of all these plans, though. The journal was never lauched and no one wrote a separate philosophy of mathematics; Schelling at least admitted that he failed to give mathematics a proper treatment in the System des transzendentalen Idealismus (1800). ${ }^{11}$ Fichte, however, who had made philosophy of mathematics a topic already in the so-called "Platner lectures"12 he gave in Jena from 1794 through 1797, continued to devote several lectures to the philosophy of mathematics during the time he read logic and metaphysics in Erlangen; ${ }^{13}$ and as late as 1812 he still outlined a scheme for a separate philosophy of mathematics, a plan he could not pursue as he died about a year later. ${ }^{14}$

Although Fichte obviously pushed harder than the brothers Schlegel, Schelling, or Eschenmayer, it is a noteworthy fact that no one involved in the project ever doubted that it was highly advisable or even mandatory to come forward with a philosophy of mathematics. This fact becomes even more baffling when one realizes that the "Fichte Circle" from around 1800 was by no means alone. The (Kantian) philosopher Jacob Friedrich Fries (1773-1843)—who should much later influence the development of Hilbert's program via Paul Bernays-started mentioning a philosophy of mathematics in his manuscripts and letters around $1795 ;{ }^{15}$ independently of Fichte, though. The same holds true for a Polish mathematician who lived in France and whose name lives on in the determinants that carry his name (the Kantian) Hoëné-Wronski (1778-1853); Wronski published a philosophy of mathematics in $1811 .^{16}$ This list, which would then include besides Kantians also students of Schelling and Hegel as well as mathematicians, would grow considerably longer if we were to include all those, who, without calling it "philosophy of mathematics", worked on the same, similar, or closely connected questions. $^{17}$

We suggest that this convergence of opinions among philosophers and mathematicians happened for a reason and that the key for understanding this phenomenon lies in a name: Kant.

What we have in mind is neither the fact that Kant tried to contribute to a persistent though suppressed undercurrent of mainstream mathematics during the 18th century, namely, the discussion of foundational issues (see, e.g., the 1786 Preisfrage on the mathematical infinite initiated by the Berlin Academy of Science); Berkeley did it before with his pamphlet The Analyst (1734). Nor is it Kant's intention to secure the working mathematician a solid foundation through philosophical analysis and reflection; Plato did it earlier with distinguishing

11 "wegen der Mathematik [...] eine große Lücke gelassen [zu haben], die ich recht wohl fühle", (Schelling, I/9.2, p. 287).

12 Cf. Vorlesungen über Logik und Metaphysik als populäre Einleitung in die gesamte Philosophie. Nach Platners Philosophischen Aphorismen (Jena, Summer 1797), in (Fichte, IV/1).

13 Cf. Institutiones omnis philosophiae, in (Fichte, II/9, pp. 124-135).

14 Cf. (Fichte, II/5, p. 583).

15 Cf. Pulte (1999, p. 74), for a summary.

16 Cf. Wronski (1811).

17 One must exercise caution, though, for not every book that has "philosophy" and "mathematics" in its title deals with philosophy of mathematics sensu stricto; many are just introductory textbooks that add some philosophical language on top of definitions and proofs; cf., e.g., Bledsoe (1873). 


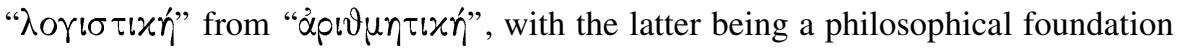
for the (mathematical) former. Rather, in the first step, Kant's innovations were to assign mathematics its own cognitive faculties, i.e., the pure intuitions of space and time. Before Kant, "[ließ] man sich gar nicht einfallen ..., daß Sinne auch a priori anschauen sollten." ${ }^{18}$ Doing so, in a second step, he claimed a distinguished, special epistemological status for mathematics.

This new Kantian epistemology with its close ties to mathematics, its promising new features, and its unclear and confusing conceptual patchwork, inspired and challenged those who worked in Kant's wake. Fichte, e.g., felt forced to deduce in his own system what Kant had simply presupposed, namely, that space is threedimensional, while Fries introduced a Hilbertian distinction according to mathematics and metamathematics. The towering figure Kant was at that time, it is thus neither a wonder nor an accident that Kantians and anti-Kantians busied themselves with something new, a philosophy of mathematics.

It is a familiar observation in the history of the science that a discipline or a community of inquiry acquires a name of its own only when it comes of age, so to speak; like British, French, and German physicists in the early 19th century, who could no longer stand to be called "natural philosophers", started to call themselves "physicist", "physicien", or "Naturforscher" respectively. The same now seems to be true for our case: philosophy of mathematics as a separate philosophical endeavor, a specialized field of its own, is a product of Kant's epistemology. And, even more, it is his creature; philosophy of mathematics in its initial shape exclusively dealt with questions that emerged from a Kantian angle and couched its answers in (Neo-) Kantian terms as well. This claim is further supported by the observation that, once Kant's epistemology had lost its initial luster, the new expression was no longer used. On and off, it made a reappearance also later in the 19th century, but only as a title for some dissertation: $X$ 's philosophy of mathematics.

Philosophy of mathematics became respectable again in the early 20th century. On one hand, Logical Empiricism replaced traditional epistemology with a different enterprise, the philosophy of science. Following Frege's lead, logical empiricists replaced the "mentalese" of traditional epistemology, i.e., the idiom of "ideas", "representations", "judgements", etc., with a study of the syntax and semantics of those languages used in scientific textbooks and research papers. Besides a common logical core all these languages were supposed to share, each language is different enough to justify a separate treatment. Unsurprisingly, we hence find what formerly was one epistemology now to be split up in various "philosophies", namely, a philosophy of physics, a philosophy of biology, a philosophy of sociology, etc. Philosophy of mathematics thus re-emerged as a discipline of its own as a byproduct of substituting traditional epistemology with a philosophy of science program.

John Stuart Mill was proud to be the first philosopher to give, unlike Locke and Hume, a comprehensive and at the same time thoroughly empiricist account of mathematics. His approach, however, fell prey to Frege's sharp criticism and was

\footnotetext{
18 "no one considered that the senses should also intuit a priori". (Kant, AA, IV, p. 375, note (=Prolegomena, A207)).
} 
hence no longer acceptable to empirical-minded philosophers in the late 19th or early 20th century. Their solution was to adopt Russell's logicist thesis that every mathematical concept can be defined in the language of logic and that every mathematical proof can be replaced by a purely logical derivation using the logical definitions of the concepts involved; hence the label "Logical Empiricism". The result is a philosophy that ascribes mathematics a special epistemological status; mathematics is just applied logic, and as such it cannot be compared with any other science.

We find most modern analytic philosophers of mathematics subscribing to the Kant-Carnap thesis (that mathematics demands a special epistemology); probably, because the unhistorical stance taken by most of them never made them question this assumption.

Like in Kant's case before, we thus see, again, that the distinguished epistemological status of mathematics is not the result of a careful inspection of what mathematics is or what mathematicians do but an artifact of a philosophical program. It does not mean to make light of their accomplishments when we state we have plenty of reasons to be neither a Kantian nor a logical empiricist. But if this is true, then we have lost any prima facie justification to assume that mathematics would require a philosophical analysis that is different from that of any other science.

We also see that - contrary to the Neo-Kantian conception of the history of philosophy that is still predominant is most quarters of philosophy-there is, if we look at the facts, no continuity in the field that would span centuries and millennia; it doesn't make sense to speak of a "philosophy of mathematics from Plato to Putnam”. Before Kant, philosophers accounted, in varying degrees, for mathematics in their systems; no doubt about it. But no one felt the need for a separate epistemological treatment. It would be an anachronism to ascribe to them a philosophy of mathematics sui generis, thereby projecting back onto them a conception they simply could not have. Philosophy of mathematics as we know it today is a product of Logical Empiricism; it emerged in a unique historical situation and was meant to satisfy specific philosophical needs of the time. To ignore this fact means to fake history and to work within an outdated philosophical framework instead of questioning it.

A historical lesson from the ontology of mathematics. In the times before Descartes, it went mostly without saying that a soul without a body is an incomplete substance and that assuming immortality of the soul would therefore require the resurrectionem carnis of the Apostle's Creed. Accordingly, and in opposition to what Boëthius and Augustine had said earlier, (a student of) Thomas Aquinas defended the opinion that "certain corporeal places are appointed to them [the souls]". ${ }^{19}$ Descartes, who, unlike Thomas, was under no obligation to defend doctrines about the purgatory, widened the traditional gap between body and soul even further by declaring the res cogitans to have no spatial extension or location whatsoever. Both Descartes and Aquinas agreed, though, that, while perception requires the cooperation of both body and soul, "quaedam operationes sunt animae,

19 (Aquinas, Summa theol., p. 3 suppl., quest. 69, art. 1). 
quae exercentur sine organo corporali, ut intelligere et velle". ${ }^{20}$ and that "huiusmodi potentiae necesse est quod maneant in anima, corpore destructo". ${ }^{21}$

The philosophical and religious backdrop of this view, however, has gone missing. Supporting religious beliefs are either waning, or contravening scientific results, or both; and philosophy follows suit. Asked either to abandon Cartesian dualism or to renounce mental causation-for, by scientific lights, the two are not compatible with each other ${ }^{22}$ - it is ontological dualism that usually has to go, for this leaves us with a physicalism that we expect to cohere well with the scientific knowledge we embrace. ${ }^{23}$

We thus face a situation in which an important fragment of our everyday language, the "mentalese" of folk psychology, has lost its semantics; for the ontological dualism that this language presupposes and which underlies our mindbody distinction and is so well-entrenched in Western thought is no longer available. One important task for the philosophy of mind, provided it doesn't waste its time on some vain rearguard actions, is hence to work out the details of a new semantics for the mentalese we speak and which we cannot dismiss.

Philosophy of mathematics seems to lag behind. Given the above-mentioned assumptions on the soul, combined with an ontology that rested, basically, on an Aristotelian notion of substance, mathematical Platonism was a very natural position to adopt. And most mathematicians and philosophers continue to speak some sort of "platonese", for it is, no doubt, a very convenient language to speak when it comes to mathematics. But 'platonese' has lost its semantics like 'mentalese' did. We no longer embrace, like Aquinas did in the above-cited quotations, the idea of an immortal non-physical soul that is the seat of reason and harbors, among other eternal entities, mathematical objects; reasoning and its objects are, ultimately, functions of the brain and products of its activity. ${ }^{24}$ In short, an ontology of mathematics that assumes an immortal soul harboring mathematical objects doesn't seem to be available any longer.

The claim that mathematics is a human activity that creates its own objects is further supported by a look at the history of mathematics_-provided, of course, we look without the familiar Plato-tinted spectacles but

\footnotetext{
20 "Some operations of the soul are performed without a corporeal organ, like reasoning and willing" (Aquinas, Summa theol., p. 1, quest. 77, art. 5).

21 "these powers must remain in the soul, after the destruction of the body" (Aquinas, Summa theol., p. 1 , quest. 77, art. 8).

22 Any two of the following propositions will contradict the third:

(1) Mental phenomena are non-physical phenomena;

(2) Mental phenomena are causal efficient among physical phenomena;

(3) The realm of physical phenomena is causally closed
}

(taken from Bieri (1981, p. 5)); cf. Kim (2006, Chaps. 2 \& 7) for a more detailed overview of the arguments that cause most people to reject dualism and favour some sort of physicalism instead.

23 Cf., e.g., Churchland (1986, 2002).

24 Cf., e.g., Dehaene et al. (2004). Accordingly, an important task for the philosophy of mathematicsprovided it doesn't waste its time on vain rearguard actions either-is, then, to work out the details of a new semantics for the platonese we still prefer to speak. Devlin's paper in this issue attempts just this; see also Buldt ( $\infty$ a) for a different, though similar, approach with the same goal. 
[...] take a view of mathematical activity drawn from observed facts in opposition to the normative assertions of certain philosophers of mathematics. An honest conception [...] must emerge from a dispassionate examination of what mathematicians do, rather than from what mathematicians say they do, or from what philosophers think mathematicians ought to do".

(Rota 1991, p. 108)

Let us look at the concept of continuity as an example:

The idea of a mathematical continuum is intimately connected to and has actually been motivated by physics in general and by questions of mathematical models for the kinematics and dynamics of bodies in particular. This holds true for the physics of Aristotle, and becomes a predominant theme in Leibniz who even made the lex continuationis, the loy de la continuité, the most basic principle to govern his research in mathematics, the sciences, and philosophy. The idea was to model physical change with the help of continuous functions such that changes in the physical world (say, location, velocity, potential energy, etc.) are reflected by a corresponding change of function values. Leibniz worked with the notion of an infinitesimal, an infinitely small quantity, and mathematical research was done within this conceptual framework for nearly two centuries.

Only a few complained about the lack of a more rigorous conceptual foundation, but when the climate began to change because mathematicians found themselves unable to make any progress unless more rigorous definitions had replaced the language of infinitely small quantities, Cauchy satisfied his own research needs by introducing the convergence criterion for sequences that still carries his name. ${ }^{25}$ Subsequent conceptual honing finally led to Weierstrass' famous $\varepsilon-\delta$-technique of defining mathematical properties of continuity (and differentiability). The new language of limits, however, required in turn a more rigorous definition of the concept of real number which was delivered by Dedekind among others. And because it worked out well, mathematicians were happy to accept these new notions and to identify the continuum with the set of real numbers.

Further research, however, suggested that the continuity of a function is not really a property of the function but of the underlying space; for, provided one has appropriate spaces $S$ and $T$, every function from $S$ onto $T$ will be continuous, say, if $S$ has the discrete (every subset is open) or if $T$ has the indiscrete topology (only the set itself and $\varnothing$ are open). This is why we currently conceive of continuity as a topological property and define continuity accordingly in terms of open sets and their preimages (which have to be open again). ${ }^{26}$

We hence witness major conceptual changes for the notion of continuity (and, along with that, the notion of a function and other related concepts.

- In the wake of Leibniz the continuity of a function, or, to be more precise, the continuity of the graph of a function results from the fact that everything obeys the law of continuity. Neither is it necessary to prove a function to be continuous

\footnotetext{
${ }^{25}$ A sequence $\left\langle a_{n} ; n \in \mathbb{N}\right\rangle$ is convergent if and only if for every $\varepsilon>0$ there is a number $n_{\varepsilon}$ (so large) such that $\left|a_{n}-a_{m}\right|<\varepsilon$, for all $m, n>n_{\varepsilon}$.

${ }^{26}$ Cf., e.g., Crossley (2005, p. 17 seq).
} 
(why belabor the obvious) nor to guarantee its continuity by, say, reducing it to a paradigmatic case. Everything that is continuous, and if two arbitrary curves intersect, then there must be a point in which they intersect. The prevailing general point of view in ontology is monistic, everything shares the property of being continuous. Kant turned this view into a law a priori by making it, respectively what he called the "anticipations of perception", 27 a synthetic principle of pure understanding.

- In the tradition of Cauchy, Cantor, Dedekind, and Weierstrass continuity is the property of a function (now conceived of as a set of $n$-tuples) which is defined on a point set continuum. The continuity of a function is no longer guaranteed but has to be established, and any other type of continuity is reduced to the set of reals as the paradigmatic case of continuity. The prevailing general point of view in ontology is bottom-up, everything is built from up from certain basic objects (usually sets).

- Currently, the continuity of a function is conceived of as being induced by properties of the underlying space; continuity is a topological property. Previous questions about the point set continuum as the one distinguished model of continuity have lost much of their former luster since Cohen forcing has shown that the continuum, understood as $2^{\omega}$, can be anything, say, that is not cofinal with $\omega$ (like, $\omega_{2}, \omega_{\omega_{1}}$, etc.) or that is weakly inaccessible. ${ }^{28}$ The prevailing general point of view in ontology is structural, while objects no longer really matter; this approach shows itself most clearly in category theory.

Examples like this, which could easily be multiplied, make us believe that the idea of unchangeable mathematical objects is a red herring. The fact that in mathematics most results carry over from one period to the next doesn't imply that the objects remain the same, or that a long-winding and sometimes crooked road eventually leads us to the discovery of their true nature. Rather, it seems advisable to admit that, if some old mathematical order persists, then it "does so under different terms, in radically altered or expanded contexts. (Dauben 1984, p. $52) "$

If we face the fact that we can no longer build our ontology of mathematics on the conception of an immortal soul harboring mathematical objects, then taking a fresh look (i.e., without Platonic blinders) at the history of mathematics will provide us with further evidence that

mathematics is man-made; its vital basis is the social inter-action of mathematicians in their scientific community. No mathematician starts from nothing. He has to build upon mathematical tradition. In the course of his mathematical education, be it formal or otherwise, he acquires a 'tacit knowledge' about mathematics, the way to talk about it, its aims and methods, which enables him to communicate with his fellow mathematicians. He

\footnotetext{
27 "In allen Erscheinungen hat das Reale, was ein Gegenstand der Empfindung ist, intensive Größe, $d . i$. einen Grad" (In all appearances, the real that is an object of sensation has intensive magnitude, that is, a degree) (Kant, AA, III, p. 151 (=CPR, B 207)) (emphasis suppressed).

28 Cf. Kunen (1980, pp. 209 seq).
} 
becomes a member of their community, more or less conforming to its way of doing things and to its norms. He strives for recognition by his colleagues.

(Mehrtens 1976, p. 30)

Consequently, as mentioned above, we embrace a very broad approach to the philosophy of mathematics that includes, among others, cognitive science, math education, and sociology.

Also, if we take the idea of the historicity of mathematics seriously, then we can no longer treat Plato (or others) as one of ours peers. Mathematics at Plato's times was different from ours, ${ }^{29}$ and we cannot expect to communicate well across the centuries; proving the 'same' result by gnomons and by induction indicates that we are talking about two different concepts that have not much more in common than some number names. We understand perfectly well that a naive substance ontology underlying the 'platonese' mathematicians came to speak suggests otherwise; but besides the concerns that arise from taking the historicity of mathematics seriously, we ask to bear in mind that such a substance ontology doesn't sit well with modern structuralism either and is at odds with the view from category theory; ${ }^{30}$ in short, it is hardly compatible, for mathematical reasons alone, with modern mathematics.

\section{Methodological Issues of Philosophy of Mathematics}

We mentioned in Sect. 1 above why we think sociological studies are important; a point that was reaffirmed in Mehrtens's statement that the "vital basis" of mathematics is "social interaction of mathematicians in their scientific community". If this is indeed the case, then one should expect that the scientific community of mathematicians is the object of sociological studies. What we find, however, is that in general the sociology of mathematics is severely underrepresented in the field of sociology of science. ${ }^{31}$

Some of the central questions of philosophy of mathematics, in particular those related to mathematical practice, have an empirical core, though. Some of the statements that one finds in philosophical texts about mathematics are empirical claims, and the most natural way to find out whether they are true or false is to test them. Very few philosophers of mathematics take this last step, and it is not an easy step to take, as data on these questions are not readily available.

Philosophy of mathematics, like other areas of philosophy, relates phenomena (in this case, mathematics) to a philosophical theory. Whether the philosophical theory is correct or not is not independent of the phenomena. Analytic Philosophy, and in

\footnotetext{
${ }^{29}$ Remember, e.g., that, probably due to Eleatic thought, the Greeks considered natural numbers to be composed out of units; thus two was the first natural number, but neither one nor zero were. At the same time they thought of numbers in geometrical terms and not as abstract quantities: "With rare exceptions [...] the theory of numbers was only treated in connexion with geometry, and for that reason only the geometrical form of proof was used [...]" (Heath 1921, p. 16).

${ }^{30}$ Cf., e.g., Awodey (2004).

${ }^{31}$ Cf. Heintz (2000, p. 9): "[d]ie Soziologie [begegnet] der Mathematik mit einer eigentümlichen Mischung aus Devotion und Desinteresse" (sociology approaches mathematics with a peculiar mix of humbleness and indifference). Her study thus reconfirms the earlier assessment of Latour (1987, pp. 245 seq).
} 
particular philosophical logic, often analyze phenomena by a technique that one could call, in analogy to the well-known technique of mathematical modelling in applied mathematics, conceptual modelling, philosophical modelling, or logical modelling. This technique consists of a number of natural steps, one of which is to confront the philosophical model with the phenomena. We claim that in many areas of philosophy, especially in the case of philosophy of mathematics, this step is highly underdeveloped.

In a joint paper with Eva Wilhelmus, two of us proposed the development of a philosophical study of mathematics as a discipline based on empirical facts (Löwe et al. 2007). Such an approach could be called "naturalistic", as in Maddy (1997), or it could be called a "Second Philosophy of Mathematics", as in Maddy (2007). We shall use the label "Empirical Philosophy of Mathematics" in order to stress the fact that there is actual empirical work to be done. The project Empirical Philosophy of Mathematics consists of a theoretical foundation together with a potentially unlimited number of questions and practical projects. Some first steps towards such an Empirical Philosophy of Mathematics have been documented in Löwe and Müller (2008) and Löwe (2007). The theoretical foundation should contain a sustained argument for the methodology of conceptual modelling, and should contain in particular an argument for the necessity to empirically check those philosophical theories that were established via this method. In Wilhelmus (2007), the author investigated the philosophical question "Is formalizability of an argument a necessary condition for mathematical knowledge?", using the empirical method of an online questionnaire, and gave a negative answer. ${ }^{32}$

Mathematical modelling. The notion of a model has acquired a prominent place in contemporary philosophy of science. A great variety of uses of the term "model" has been studied. ${ }^{33}$ There is widespread agreement that models play a crucial rôle in scientific practice, and that a fair amount of that practice consists in modelling. We shall describe the practice of mathematical modelling, as exemplified in the sciences, not to give an in-depth account of mathematical modelling, but to highlight some of its features relevant for the present discussion.

One can formulate an iterative method of mathematical modelling as we find it in applications of mathematics to science:

- Step 1. One starts with a class of models that appear to be reasonable candidates. This class may be determined by pre-theoretical insight, or by earlier steps in the iteration.

- Step 2. One collects data and tries to achieve a best fit within the available class of models.

- Step 3. One determines the goodness of fit and will either be satisfied or revert to step 1, having chosen a different class of models.

Statistical tools have been developed for assessing the "goodness of fit" of models and data, and there is usually an additional layer of modelling for the data

\footnotetext{
32 Cf. Löwe et al. (2007) for an overview of the results with some theoretical background.

${ }^{33}$ Cf. Frigg and Hartmann (2006) for an overview.
} 
themselves (in order to handle measurement errors). The crucial step in mathematical modelling is to confront the selected model with the data. As every scientist will be proud to say, honesty with respect to that step is the hallmark of good science.

Conceptual Modelling. Viewed abstractly, the aim of establishing a "philosophy of $X$ " is quite similar to finding a "model for $Y$ " in the sciences: One wishes to gain theoretical insight into (some) aspects of a certain phenomenon by representing them in a specific way. To give an example: One of the key questions in epistemology is what knowledge is. The traditional conception of knowledge as justified true belief (dating back to Plato's Meno) was challenged by data taking the form of counterexamples: Gettier constructed plausible scenarios in which persons have justified true belief, but not knowledge (Gettier 1963). The ensuing debate led to a repertoire of test cases that serves as a benchmark for theories of knowledge. But the issue of what are the data and what is the model is much more subtle than it is in the typical case of modelling in the natural sciences. Both the traditional model of knowledge as justified true belief and the data in the form of counterexamples derive from our intuitions about knowledge, and thus are two aspects of the same phenomenon. Testing one against the other might involve some circularity.

If one wishes to mirror the scientific method of mathematical modelling in a philosophical context, one needs to be very careful with the source and the nature of both theory and data. Thus, conceptual modelling of a phenomenon $X$ takes the form of an iterative process:

- Step 1. Theory formation. Guided by either a pre-theoretical understanding of $X$ or the earlier steps in the iteration, one develops a structural philosophical account of the phenomenon $X$, keeping track of the source and the development of the theory in order to be able to distinguish it from the data in step 2 .

- Step 2. Phenomenology. With a view towards step 3, one collects independent data about the phenomenon $X$ that is able either to corroborate or to question the current theory.

- Step 3. Reflexion. In a circle between the philosophical theory, its formation process, and the phenomenological data, one assesses the adequacy of the theory and potentially revises it by reverting to step 1 .

In many debates of contemporary epistemology, Step 2 consists of a presentation of the author's intuitions about the case at hand, possibly supported by anecdotal evidence. While this may be enough if there is widespread consensus about the analysis, a different solution needs to be found if one has to decide between competing models. The obvious solution, in view of the scientific modelling practice, is to supply more data from a more varied range of sources, including data established via accepted empirical methods. On this view, the key to successful conceptual modelling lies in strengthening Step 2 of the above iterative scheme. In epistemology, the necessary data might be supplied, e.g., by empirical linguistics, sociology, or cognitive science.

As mentioned above, sociology of science has, with few exceptions, shunned away from taking mathematics as an object of study-mostly for a simple reason: preconceived philosophical convictions made such studies appear senseless or impossible. The first large-scale socio-empirical study published was Heintz's work 
about the culture and practice of mathematics as a scientific discipline. ${ }^{34}$ The work of Wilhelmus (2007) shows that this approach can yield genuine philosophical conclusions.

Cognitive science has to offer a number of interesting results with various philosophical implications as well. For instance, the cognition of basic mathematical operations has been intensively studied. ${ }^{35}$ This work, however, stays very much within the confines of the algorithmic or computational part of mathematics, and does not touch upon higher mathematics. As explained in Sect. 1 above, it is mathematics as a proving discipline that is in our focus. Developing a cognitive theory of what is happening in the proving mind is central to understanding the special status of mathematics. In his paper "A mathematician reflects on the useful and reliable illusion of reality in mathematics" in this special issue, Keith Devlin speculates on the philosophical conclusions one could derive from such a deeper understanding of the cognitive processes involved in research-level mathematics. We shall come back to his paper at the end of our list of contributions.

\section{The Contributions of This Special Issue}

Although the contributions in this issue are arranged by alphabetical order, we introduce them here in a somewhat more systematic fashion. We start with Larvor's paper on the rôle of history and continue with three papers that have an historical component (Schlimm and Easwaran on axiomatics, Bråting \& Pejlare on visualization). Then we introduce two papers that touch on experimental mathematics (Van Bendegem \& Van Kerkhove and Baker) and conclude with Devlin's paper on "neuromathematics".

Brendan Larvor's contribution entitled "What can the philosophy of mathematics learn from the history of mathematics" is considering whether the marriage between the philosophy and the history of mathematics can be a happy one. One overarching theme he spells out in various details throughout his paper is that "historians [as opposed to philosophers] do not explain events by subsuming them under general schemes, but rather by setting events in their proper historical contexts". By further juxtaposing the different approaches of history and philosophy, he then tries to promote a philosophy of mathematics that does no longer proceed blindly, but is enlightened by methodological insights from history; his final plea is for a "historically and self-aware philosophy".

Dirk Schlimm's research project on the relationship between the axiomatic method and historical developments in mathematics is the background of his paper "On the importance of asking the right research questions: Could Jordan have proved the Jordan-Hölder Theorem?". The paper corrects a long-standing though erroneous "result" in the historiography of modern algebra, viz. that Jordan was

\footnotetext{
34 Before Heintz (2000), Markowitsch used qualitative sociological studies (interviews with mathematicians) in his Markowitsch (1997).

35 Cf., e.g., (Koedinger and Anderson 1990; Siegler and Stern 1998; Neth 2004; Anderson 2005; Landy and Goldstone $\infty \mathrm{a}$; Landy and Goldstone $\infty \mathrm{b})$.
} 
“conceptually unable" to prove Hölder's generalization of his theorem providing an important case study of how abstraction works in mathematical practice.

In his "The role of axioms in mathematics", Kenny Easwaran wants to correct another aspect that received wisdom has to offer on axiomatics. Building on Feferman's distinction between structural axioms (say, for algebraic entities) and foundational axioms (say, for numbers or sets), he assumes that the question is not whether we need new structural axioms or not (we always will) but whether or not we need new foundational axioms. The thesis he defend and investigates from various angles is that foundational axioms have an important social rôle to play within the community of mathematics: they save mathematicians (useless) philosophical controversy and allow them to do instead what they love to do: proving new theorems.

In their paper "Visualization in Mathematics", Kajsa Bråting and Johanna Pejlare bring together historical and empirical approaches to one of the most hotly debated questions in the philosophy of mathematics: What is the rôle of visualization in mathematics? From a historical, diachronic perspective, this may amount to asking: Which rôle has visualization played in the historical development of mathematics? How has the mathematical community assessed visualization as a part of mathematical practice, and how did this assessment change over time? From a synchronic perspective, the empirical side of the question about visualization can focus on a multitude of facets, too: The actual use of different types of visualization in various mathematical contexts, the use of visualization in mathematics education, cognitive mechanisms involved in the use of visualization, etc. Accordingly, the authors bring together two historical case studies on the use of visualization in the 17 th and the 19th century and an empirical study on first year students' difficulties with interpreting visualizations.

The first historical case study presented pertains to the criticism and the eventual decline of visualization in mathematics triggered by geometrical and analytical argumentations drifting apart in the course of the rigourization of analysis in the 19 th century. The second case study, focussing on visual argumentation in 17th century mathematics, brings to the fore the need for an interpretation of visualizations. Interpretation is also the key aspect of diagrammatic reasoning that the authors put forward against Giaquinto's attempt at distinguishing visual from non-visual branches of mathematics. This discussion leads naturally to their presentation of an empirical study conducted among first-year university students. It turns out that in themselves, the pictures given to the students are not sufficient to show them what is happening in a construction; instead, a certain skill of interpreting the pictures, which would be acquired by studying mathematics, appears to be a necessary precondition for getting the right results.

"Pi on Earth" is a paper by Jean-Paul Van Bendegem and Bart Van Kerkhove which emphasizes a completely different link between mathematics and the empirical world than what we discussed in Sect. 3 above. Whereas we stressed the importance of empirical research for the philosophy of mathematics, Van Bendegem and Van Kerkhove stress the empirical character of some mathematical practices. They discuss non-formal arguments, mathematical experiments, inductive reasoning, and probabilistic proof. In the end, they discuss two hypothetical scenarios and their 
consequences for the empirical character of mathematics. In the second scenario, they employ Malament-Hogarth spacetimes, a theory that recently gained a lot of attention in the computability community as these solutions to the Einstein equations of General Relativity allowing for an infinite amount of time to pass in what is a finite amount of time for an observer. They use these scenarios to argue that mathematical practice depends on contingent facts about the physical world.

In his "Experimental Mathematics", Alan Baker develops a theme from another paper by Van Bendegem (1998) and asks for the scope and the philosophical implications of the new field of experimental mathematics. Does the emergence of this field endanger the traditional foundations of mathematics? In his discussion of the scope of experimental mathematics, Baker revisits some of the topics discussed in the paper by Van Bendegem and Van Kerkhove, both number-crunching and inductive arguments show up. However, whereas Van Bendegem and Van Kerkhove conclude by saying that experimental methods and an empirical basis form an indispensible backdrop for mathematical practice, Baker goes the other way and says that the fact that mathematicians use experiments in the context of discovery is "compatible with the view that mathematics is a priori and deductive at its core".

We end our list of contributions to this special issue with Keith Devlin's intriguing paper "A mathematician reflects on the useful and reliable illusion of reality in mathematics". Devlin very clearly states that the paper "is not intended to be a 'philosophy paper' ... but very much in ... the spirit of the GAP.6 workshop, ... rais[ing] possibilities that might merit further consideration". Devlin goes back to one of the central observations about mathematical research practice, the Widerstandsempfinden, repeatedly mentioned in Sect. 1 and also elaborated in Buldt $(\infty \mathrm{a})$. This Widerstandsempfinden is one of the reasons for mathematicians to adopt the belief that mathematics is not just a mental figment, but rather about the manipulation of real objects. Devlin asks where this resistance comes from and decides to look for its origin at the human brain. We are of course far from understanding the way the human brain actually works, and thus any reduction of the Widerstandsempfinden to the workings of the brain must be preliminary, but Devlin's ideas certainly are stimulating and in accord with current neuroscience.

Open Access This article is distributed under the terms of the Creative Commons Attribution Noncommercial License which permits any noncommercial use, distribution, and reproduction in any medium, provided the original author(s) and source are credited.

\section{References}

Anderson, J. R. (2005). Human symbol manipulation within an integrated cognitive architecture. Cognitive Science, 29(3), 313-341.

Aquinas, T. (1912-1936). Summa theologica, tr. Fathers of the English Dominican Province, Burns, Oates \& Washbourne, London.

Awodey, S. (2004). An answer to G. Hellman's question 'Does category theory provide a framework for mathematical structuralism?' Philosophia Mathematica, 12(3), 54-64.

Bieri, P. (1981). Generelle Einfürung. In P. Bieri (Ed.), Analytische Philoosphie des Geistes (pp. 1-28). Hain: Königstein/Ts.

Bledsoe, A. T. (1873). The philosophy of mathematics, with special reference to the elements of geometry and the infinitesimal method. Philadelphia: J. B. Lippincott. 
Buldt, B. (2004). What has history to do with it? Remarks on the philosophy of mathematics. Antrittsvorlesung, Konstanz, 21 June 2004.

Buldt, B. ( $\infty$ a). Mathematical practice and platonism: A phenomenological perspective, submitted.

Buldt, B. ( $\infty$ b). What does time tell in (intuitionistic) mathematics?, To appear in the Proceedings of the Conference: 100 ans d'intuitionisme, Cerisy, 5-12 June 2007.

Buldt, B., Van Kerkhove, B. ( $\infty)$. Questioning the historicity of mathematics-Evolution or revolution?, in preparation.

Churchland, P. S. (1986). Neurophilosophy: Toward a unified science of the mind-brain. MIT Press: Cambridge MA.

Churchland, P. S. (2002). Brain-wise: Studies in neurophilosophy. Bradford Book/MIT Press: Cambridge MA.

Crossley, M. D. (2005). Essential topology. London: Springer.

Dauben, J. W. (1984). Conceptual revolutions and the history of mathematics: Two studies in the growth of knowledge. In M. Everett (Ed.), Transformation and tradition in the sciences (pp. 81-103). Cambridge: Cambridge University Press. Reprinted in: Gillies (1992, pp. 49-71).

Dehaene, S., Molko, N., Cohen, L., \& Wilson, A. J. (2004). Arithmetic and the brain. Current Opinion in Neurobiology, 14, 218-224.

Ernest, P. (1998). Social constructivism as a philosophy of mathematics. Albany NY: SUNY Press.

Fallis, D. (2003). Intentional gaps in mathematical proofs. Synthese, 134, 45-69.

Faltings, G. (1995). The proof of Fermat's last theorem by R. Taylor and A. Wiles, Notices of the American Mathematical Society, 42(7), 743-746.

Frigg, R., \& Hartmann, S. (2006). Models in science. In E. N. Zalta (Ed.), Stanford encyclopedia of philosophy, Spring 2006 Edition.

Gillies, D. (Ed.). (1992). Revolutions in mathematics. Oxford: Clarendon Press.

Gettier, E. (1963). Is justified true belief knowledge? Analysis, 23, 121-123.

Grattan-Guinness, I. (2004). The mathematics of the past: Distinguishing its history from our heritage. Historia Mathematica, 31, 163-185.

Heath,T. L. (1981). A history of greek mathematics, Vol. 1, Dover, New York, 1981 (first Clarendon Press, Oxford, 1921).

Heintz, B. (2000). Die Innenwelt der Mathematik. Zur Kultur und Praxis einer beweisenden Disziplin. Springer: Wien.

Hoëné-Wronski, J. M. Introduction à la philosophie des mathématiques et technie de l'algorithmie, Courcier, Paris, 1811 (repr.: Oeuvres mathematiques de Hoëne Wronski, tome 1, Hermann, Paris, 1925).

Jaffe, A., \& Quinn, F. (1993). Theoretical mathematics": Toward a cultural synthesis of mathematics and theoretical physics. Bulletin of the American Mathematical Society 29, pp. 1-13, 1993. Replies: (Thurston, 1994); M. Atiyah et al., Responses, Bulletin of the American Mathematical Society, Vol. 30, pp. 178-207, 1994; A. Jaffe, F. Quinn, Response, Bulletin of the American Mathematical Society, Vol. 30, pp. 208-211, 1994.

Kant, I. Gesammelte Schriften (=Akademieausgabe, AA), Ed. Königlich Preußische Akademie der Wissenschaften, de Gruyter, Berlin, 1902 seqq.

Kim, J. (2006). Philosophy of mind. Cambridge MA: Westview Press.

Koedinger, K. R., \& Anderson, J. R. (1990). Abstract planning and perceptual chunks: Elements of expertise in geometry. Cognitive Science, 14, 511-550.

Korten, H., \& Ziche, P. (Eds.), Schelling, Friedrich Wilhelm Joseph: Historisch-kritische Ausgabe, Reihe I: Werke, Band 9, 1-2: System des transscendentalen Idealismus (1800), Frommann, Stuttgart-Bad Cannstatt, 2005.

Kunen, K. (1980). Set theory. An introduction to independence proofs. Amsterdam: North-Holland.

Landy, D., \& Goldstone, R. L. ( $\infty$ a). Formal notations are diagrams: evidence from a production task, to appear in: Memory and Cognition.

Landy, D., \& Goldstone, R. L. ( $\infty$ b). How abstract is symbolic thought?, to appear in: Journal of Experimental Psychology: Learning, Memory, and Cognition.

Latour, B. (1987). Science in action. How to follow scientists and engineers through society. Cambridge MA: Harvard University Press.

Lauth, R., \& Gliwitzky, H. (Eds.). (1973). Johann Gottlieb Fichte, Gesamtausgabe der Bayerischen Akademie der Wissenschaften, Band III, 4: Briefe 1799-1800, Frommann, Stuttgart-Bad Cannstatt. 
Lauth, R., \& Gliwitzky, H. (Eds.). (1977). Johann Gottlieb Fichte, Gesamtausgabe der Bayerischen Akademie der Wissenschaften, Band IV, 1: Kollegnachschriften 1796-1798, Frommann, StuttgartBad Cannstatt.

Lauth, R., \& Gliwitzky, H. (Eds.). (1979). Johann Gottlieb Fichte, Gesamtausgabe der Bayerischen Akademie der Wissenschaften, Band II, 5: Nachgelassene Schriften 1796-1801, Frommann, Stuttgart-Bad Cannstatt.

Lauth, R., \& Gliwitzky, H. (Eds.). (1993). Johann Gottlieb Fichte, Gesamtausgabe der Bayerischen Akademie der Wissenschaften, Band II, 9: Nachgelassene Schriften 1805-1807, Frommann, Stuttgart-Bad Cannstatt.

Löwe, B. (2007). Visualization of ordinals. In T. Müller, A. Newen (Eds.), Logik, Begriffe, Prinzipien des Handelns-Logic, concepts, principles of action (pp. 64-80). Paderborn: Mentis.

Löwe, B., \& Müller, T. (2008). Mathematical knowledge is context-dependent, to appear in: Grazer Philosophische Studien, 76.

Löwe, B., Müller, T., \& Wilhelmus, E. (2007). Mathematical knowledge: a case study in empirical philosophy of mathematics, ILLC Publications, PP-2007-32.

Mackenzie, D. (2006). The Poincaré Conjecture-Proved. Science, 314(5807), 1848-1849.

Maddy, P. (1997). Naturalism in mathematics. Oxford: Oxford University Press.

Maddy, P. (2007). Second philosophy: A naturalistic method. Oxford: Oxford University Press.

Markowitsch, J. (1997). Metaphysik und Mathematik. Über implizites Wissen, Verstehen und die Praxis in der Mathematik. PhD Thesis, Universität Wien.

Mehrtens, H. (1976). T. S. Kuhn's theories and mathematics: A discussion paper on the 'New Historiography' of mathematics, Historia Mathematica, 3, 297-320. Reprinted in: Gillies (1992), pp. $21-41$.

Morgan, F. (2005). Book review: Kepler's conjecture and Hales's proof. Notices of the American Mathematical Society, 52(1), 44-47.

Neth, H. (2004). Thinking by doing: interactive problem solving with internal and external representations. PhD Thesis, Cardiff University, UK.

Pulte, H. (1999). ‘... sondern Empirismus und Spekulation sich verbinden sollen': Historiographische Überlegungen zur Rezeption der Friesschen Wissenschaftstheorie und Naturphilosophie. In W. Hogrebe \& K. Herrmann (Eds.), Probleme und Perspektiven von Jakob Friedrich Fries' Erkenntnistheorie und Naturphilosophie (pp. 55-92). Lang, Frankfurt.

Rota, G.-C. (1991). The concept of mathematical truth. Review of Metaphysics, 44(3), $483-494$. Reprinted as: G.-C. Rota (1997). The phenomenology of mathematical truth. In G.-C. Rota, F. Palombi (Eds.), Indiscrete thoughts (Chap. X, pp. 108-120). Boston: Birkhäuser.

Siegler, R. S. (1998). Elsbeth Stern, Conscious and unconscious strategy discoveries: A microgenetic analysis. Journal of Experimental Psychology: General, 127(4), 377-397.

Susanne, P. (2006). Mathematics-Cultural product or epistemic exception?. In B. Löwe, V. Peckhaus, \& T. Räsch (Eds.), Foundations of the formal sciences $I V$, The history of the concept of the formal sciences. London: College Publications [Studies in Logic 3], pp. 217-232.

Thurston, W. P. (1994). On proof and progress in mathematics. Bulletin of the American Mathematical Society, 30, 161-177.

Van Bendegem, J.-P. (1998). What, if anything, is an experiment in mathematics?. In D. Anapolitanos, A. Baltas, \& S. Tsinorema (Eds.), Philosophy and the many faces of science (pp. 172-182). London: Tsinorema, Rowman \& Littlefield.

Wilhelmus, E. (2007). Formalizability and knowledge ascriptions in mathematical practice. ILLC Publications, PP-2007-24. 